\title{
POP ART DI INDONESIA
}

\author{
Angga Kusuma Dawami \\ Program Studi Desain Komunikasi Visual \\ Fakultas Bahasa dan Seni, Universitas Indraprasta PGRI \\ akdawami@gmail.com
}

\begin{abstract}
Abstrak
Andy Warhol, dengan menentang industrialisasi pada tahun 1960-an, menjadikan Pop Art dikenal dan akhirnya menyebar ke segala penjuru dunia. Pop Art sebagai sebuah gaya, maupun aliran dapat dilihat bagaimana eksistensinya masuk dalam sendi-sendi kesenian modern sampai sekarang. Banyak senimanseniman visual yang akhirnya menggunakan Pop Art sebagai teknik, maupun gaya yang menghasilkan karya yang berbeda. Di Indonesia, Pop Art masuk dalam Seni Rupa Murni, dan juga dalam Desain. Semangat Pop Art pada era sekarang berbeda dengan semangat Pop Art ketika Andy Warhol memunculkannya. Tulisan ini membahas tentang sejarah Pop Art dunia yang masuk ke Indonesia. Ditemukan bahwa secara langsung maupun tidak langsung, Pop Art di Indonesia cenderung meniru Pop Art di dunia.
\end{abstract}

Kata Kunci: Pop Art, Sejarah, Desain, Seni Visual

\begin{abstract}
Andy Warhol using industrialization issues for his art in 1960s, that called as Pop Art. Pop Art known and spread in the world as an Art, new Art at that moment. Pop Art as a style can be seen how the existence into the joints of modern art world until now. There are many Visual Artists using Pop Art style and technique for making the different arts. Pop Art in Indonesia entering Fine Arts and Design style. The spirit of Pop Art in this era was different between Pop Art now and Andy Warhol show Pop Art for the first time. This paper discribes about Pop Art history that can be enter in Indonesia. The result, directly or indirectly, is PopArt tent Pop Art in the world.
\end{abstract}

Keyword: Pop Art, History, Design, Visual Art 


\section{PENDAHULUAN}

\section{Pop Art Dunia}

Pop Art atau yang biasa disebut sebagai Seni Pop, memiliki perbedaan jauh dengan Seni Populer. Walaupun, Seni Pop juga seni yang populer pada masanya. Kita bisa menyebutkan relalisme itu merupakan Seni Pop pada masanya, namun Realisme bukanlah Seni Pop yang diangkat oleh Andy Warhol. Antara Seni Pop dengan Seni Populer, keduanya memiliki perbedaan. Pada dasarnya, Pop Art merupakan seni yang tumbuh dan berkembang dari cabang seni rupa aliran Dadaisme. Ada yang menyebutkan bahwa Pop Art merupakan mass-culture art atau seni budaya massa. Jamie (1996:5) menjelaskan bahwa Pop Artmerupakan perlawanan dari seni-seni yang sudah mapan, yang pada ketika itu pusatnya ada di Britania Raya (kini Inggris) dan United Stated (kini Amerika Serikat).

Pop Art atau Seni Pop merupakan seni yang berkembang di Amerika yang lahir akibat tidak puas terhadap berkembangnya gaya Ekspresionisme yang melanda kaum akademis dan menempati kelas yang besar saat itu yang dianggap tidak memberikan sumbangan pada masyarakat. Maka pandangan para tokoh penentang ekspresionisme Amerika seperti; Andy Warhol, Leo Lisctenstein, Claes Oldenburg, Janes Rosenquist mencoba melemparkan karya popnya terhadap public secara besarbesaran lewat karya grafis kontemporernya, sebagai reaksi tidak puasnya pada gaya Ekspresionismeyang melanda budaya Amerika saat itu.

Seni pop berkembang sangat pesat di Amerika dan Inggris yang kemudian menjadikan budaya pop yang merebak dalam berbagai dimensi kehidupan masyarakatnya; musik, visual, terutama hasil karya seniman yang menggunakan budaya massa sebagai bahan idenya.Pada dekade 60-an, di Amerika dan Inggris terjadi ledakan pertumbuhan penduduk usia muda. Saat itu, populasi penduduk menginjak usia remaja dan dewasa, dimana saat itu disebut sebagai Youthquake (Wardana, 2012:18). Kaum muda saat itu, menganggap bahwa apapun yang dilakukan saat itu adalah benar bagi mereka, dimana hal tersebut bergesekan dengan nilai-nilai yang dianut generasi sebelumnya yang taat akan perturan. Saat itu juga, budaya massa dan konsumerisme sedang merebak, dimana kedua hal ini memberikan momentum terhadap Youthquake. Latar belakang sosial ini dianggap sebagai hal yang melatar belakangi munculnya Pop Art. Kleden (1978: 3) berpendapat bahwa orang cenderung memandang kebudayaan pop lebih sebagai penyimpangan dari pola-pola kebudayaan atau sebagai perkembangan yang prematur, yang seharusnya digalakkan dan didorong untuk mencapai tingkat kebudayaan yang semestinya. Kebudayaan pop bukanlah bentuk kebudayaan yang kurang bagus. Ia merupakan jenis lain yang hendak membedakan dirinya dari jenis yang telah mapan (majalah Prisma, Edisi bulan Mei 1987). "Pop Art juga mendefinisikan dirinya sendiri menurut pandangan seninya, dimana budaya pop juga memasuki 'Pop Art' sebagai sebuah seni yang mudah untuk dipahami oleh massa, atau masyarakat secara luas.

Di tahun 1957, seorang seniman pop Ricard Hamilton mendefinisikan (dalam Ford, 2001:40) karakteristik Pop Art; 1.Popular (didesain untuk audience secara luas); 2. Sebagai solusi jangkapendek; 3. Dapat dihabiskan (mudah dilupakan); 4. Berbiaya murah; 5. Diproduksi secara massal; 6. Muda (cocok untuk anak muda); 7. Jenaka; 8. Menggairahkan; 9. Memiliki maksud; 10. Memiliki daya tarik; 11. Bisnis yang besar. Sedangkan, menurut Sipperley 
(2013:12) adalah lukisan-lukisan Pop Art cenderung memiliki warna-warna yang mencolok, biasanya merah, kuning, dan biru.Gambar-gambar di dalam Pop Art berupa gambar yang flat seperti dalam buku-buku komik.

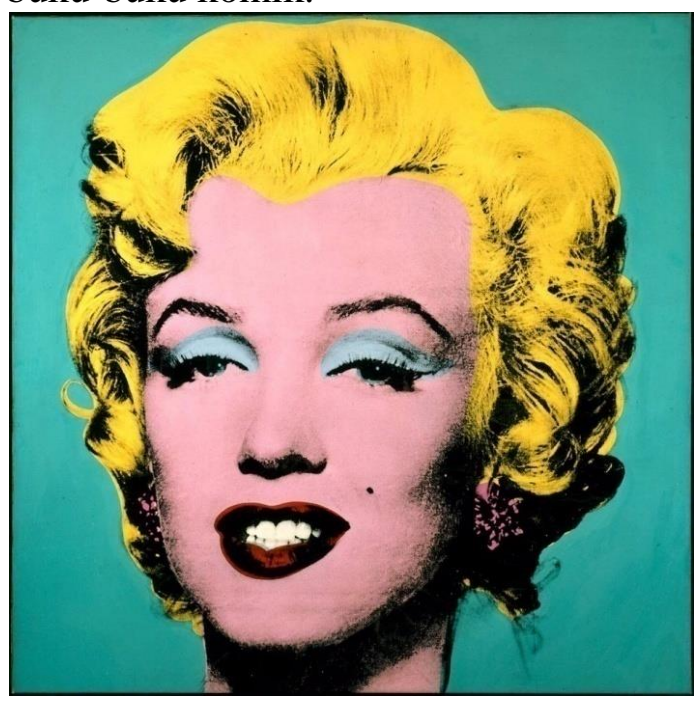

Gambar 1

Marilyn Monroe. Andy Warhol. 1962. Silkscreen screen and oil on canvas, $211.4 \times 144,7 \mathrm{~cm}$ ).

Warhol mengangkat artis yang saat itu sangat terkenal Marilyn Monroe sebagai Pop Art.

(Repro Foto Lippard (1991:xii))

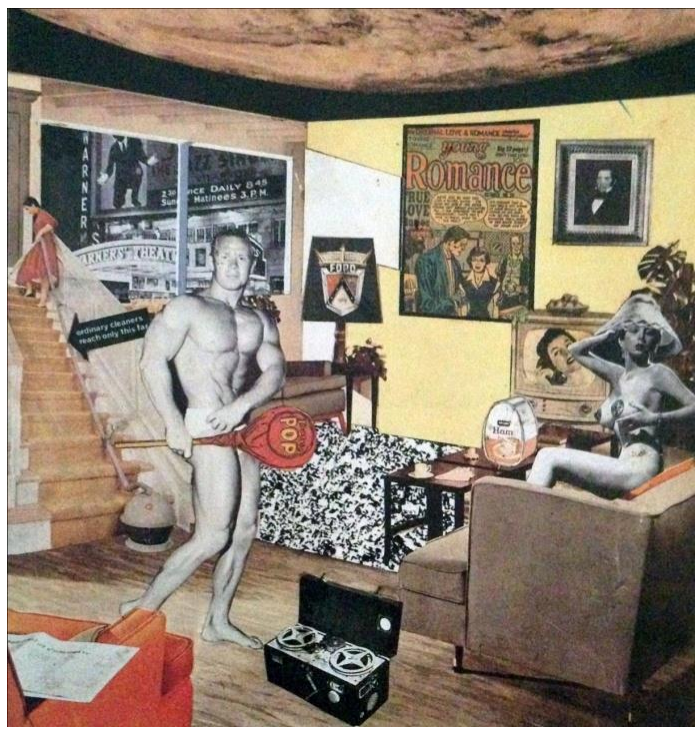

Gambar 2

Just what is that makes today's home so different, so appealing? Ricard Hamilton. 1956. Collage on Paper, 26x25 cm.Hamilton menjadikan karya ini dengan menggunakan bahan atau material yang biasa ditemui di kehidupan sehari-hari; seperti majalah, koran, dan media iklan surat kabar lainnya. (Dawami, Repro Foto dari

"History of Art" (1992:183), 2016)

Ikon-ikon dari budaya populer sepertinya sudah memperoleh dukungan di masyarakat yang menyaingi politisi dan pengusaha kala itu. Ini menjadi sangat memungkinkan bahwa pada zaman Elvis Presley dan Mickey Mouse, yang kemudian memunculkan seniman Pop Amerika seperti Andy Warhol, Roy Lichtenstein, Henri Dauman, Tom Wesselmann, Marisol Escobar, yang kemudian merebak ke seluruh dunia.

Awal kemunculan Pop Art ditandai dari karya Pop Art yang ada di London, Inggris, dimana sebuah grup yang berisikan seniman-seniman muda yang terus berkembang pada zaman seni yang sudah mapan saat itu. Di akhir 1940an, Eduardo Paolozzi seorang seniman Skotlandia, mulai membuat kolase-kolase yang menyindir, dengan menggunakan kliping-kliping dari koran-koran dan majalah-majalah Amerika. Selain itu, dia juga membuat jajaran absurd foto yang bersifat cabul yang diambil dari foto tubuh perempuan dan pria dengan gambar dari produk-massa di Amerika, seperti mobil dan botol soda.

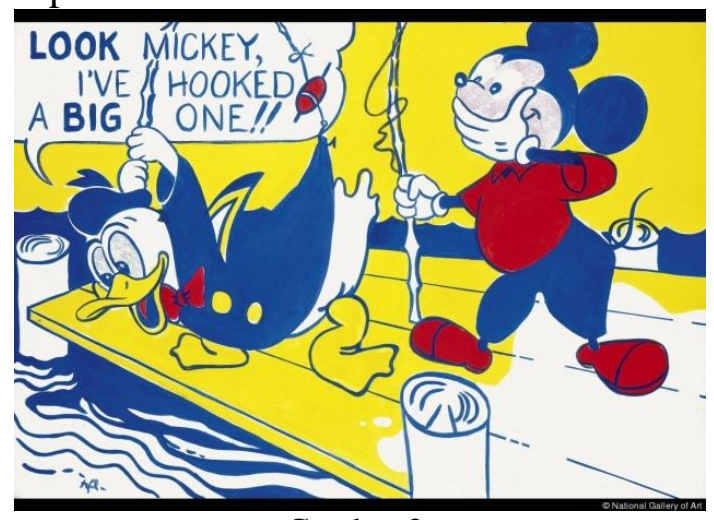

Gambar 3.

Look Mickey!Roy Lichtenstein. 1961. Oil on Canvas (silkwoven). $145 \times 211 \mathrm{~cm}$.National Gallery of Art, Washington, D.C.

(Sumber:http://blogcache1.artron.net/pada tanggal 5 Juni 2016 pukul 12:11 WIB) 


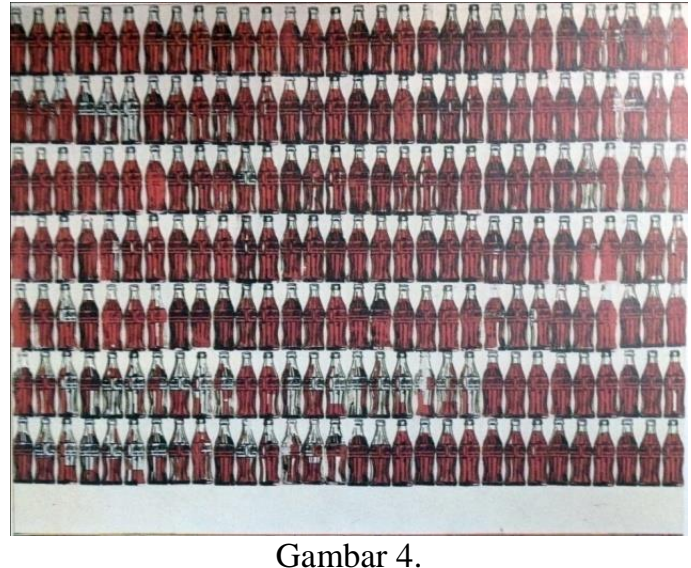

Green Coca Cola Bottles. Andy Warhol. 1962. Acrylic on Canvas (silkwoven). 145x211 $\mathrm{cm}$. Whitney Museum of American Art, New York.Repetisi diantara selebrasi-selebrasi dan pengurangan nilai. Dengan menggunakan proses silkscreening, Warhol sendiri membuatnya berulang-ulang. (Sumber: Repro Foto dari "History of Art" (1992:182))

Pada tahun 1952, Paolozzi dan sebuah grup kecil yang memiliki pemikiran yang sama sebagai "para seniman muda" dan kritikus-krikus, yang didalamnya termasuk Richard Hamilton, Nigel Henderson, Lawrence Alloway,dan Reyner Banham, memulai sebuah pertemuan informal di Institute of Contemporary Arts in London. Kelompok ini menyebut diri mereka sebagai Grup Independen, mereka bergema menggunakan Dadaism dengan menjadikan tantangan, bahwa seni ini memiliki klaim untuk memiliki status tinggi di masyarakat, dan menantang untuk bersukaria dalam kegembiraan visual dan mempengaruhi budaya populer di Amerika Serikat. The Institute of Contemporary Art (Lippard, 1991: 29), sampai hari ini, menjadi sebuah tempat berkumpul untuk seniman-senimanmuda, arsitek-arsitek, dan para penulis yang sebaliknya memiliki sebuah tempat untuk terus saling berhubungan, London memiliki sebuah tempat lain berupa sebuah kehidupan cafe seperti halnya Paris, dimana tanpa pembukaanpembukaan pameran seperti yang ada di New York.
Sejak 1960-an (Whiting, 1997:3), kepantasan pop pada penikmat $P o p$ Arttelah di sajikan sebagai dasar-dasar penolakan dan sebagai motivasi untuk mempertahankannya.Para sejarawan seni, kritikus, dengan semangat menyalahkan, memberi pujian, dan menganalisis Pop Art yang memanipulasi gambar komersial dan menggunakannya, yang diambil dari budaya konsumen. Perpaduan Pop Art dengan budaya konsumen, dalam dan dari dirinya mungkin tidak menarik untuk diperhatikan maupun berkembang dari berbagai kritik; beberapa penulis dan orang yang menyukai pameran kemudian memiliki dokumentasinya, sebuah tradisi lama dari pergerakan Modern Art dengan referensi ke budaya konsumen didahului Pop Art.

Lawrence Alloway, kritikus Amerika, menggunakan aturan kata "Pop Art" dengan konsisten dalam tulisan kritiknya. Senada dengan Ford (2001:40) bahwa:

Pop Art was an artistic movement that had begun a decade earlier in England. Lawrence Alloway, an English art critic, was the first to call certain work "Pop Art".

Hauser (1985:651) mengatakan bahwa Alloway menggunakan nama "Pop Art" untuk mendiskripsikan produk seni massa di dalam media periklanan, dari ilustrasi dalam majalah-majalah, dari film dan musik tarian. Di sisi lain, Secara sederhana, (Jamie, 1996:5) Pop Art merupakan lukisan dan gambar patung yang meminjam gambar-gambar dari budaya seni massa tinggi meniru seni rendah; seperti produk-produk komersial, produk-produk iklan, kliping-kliping dari koran, meskipun buku-buku komik dan pornografi juga menjadi sasaran untuk seniman pop, dimana didalamnya mengangkat materi-materi vulgar ke status dari budaya 'high-brow'. Kemudian 
diperkuat oleh Hauser tentang lukisan pop, bahwa:

In spite of the fairly close connection of its representatives with the cultural elite, pop painting gets its name because of the banality and triviality of its subject matter (of the orgin of its motifs in the world of standardized industrial economy), but chiefly because of the simplification of its representations-by neglecting idiosyncratic painterly values, graduated color tones, and atmospheric effects-its improvised line drawing, and the individual brush stroke. (Walaupun hubungan baik yang terepresentasi dengan budaya yang elit, lukisan pop mendapatkan posisinya dikarenakan kedangkalan dan kesepelean ide gagasan (dalam masalah ini, merupakan motif dalam dunia standarisasi ekonomi industri), tapi terutama karena penyederhanaan dari representasi-representasidengan mengabaikan nilai-nilai dalam melukis, betul tidaknya kualitas warna yang digunakan, dan efek atmosferik-dimana terdapat improvisasi gambar garis, dan sapuan individu (dari pelukis)). (Hauser, 1985:650)

Alloway juga sadar tentang adanya anti-tesis antara Pop Art dan Populer Art, tapi melihat keduanya, sebagai satu di dalam seni-rakyat; contohnya, dekorasi yang digunakan di penginapan-penginapan, hiasan dan stand pasar rakyat, dan hal-hal semacam itu, berupa variasi dalam lagu-lagu, dan literasi rongsokan-dimana untuk dan dengan orang-orang dalam 'rasa' yang dangkal dalam seni, serta Pop Art dibuat untuk orang-orang dengan segala macam 'rasa' yang bisa diterima oleh masyarakat secara luas yang dibuat oleh artis prefesional yang terlatih. Pop Art meniadakan autonomi dan tetap ada dalam pekerjaan individual seorang artis. Pop Art dipandang sebagai seni 'dangkal' yang miskin akan esensi, dilain sisi, Pop Art menjadi sebuah ekspresi pembuatnya untuk merepresentasikan kehidupan sehari-hari kepada orang-orang yang tidak biasa mendapatkan pengetahuan seni, maupun pendidikan seni. Beroposisi dengan itu, Alloway, dalam Harrison (2003:39), berdasarkan fakta-fakta yang ada dalam tanda-tanda dari pop itu sendiri terdapat bahwa keduanya (pop dan budaya populer) memiliki substansi dan ketidak-esensial dalam pandangan seni, termasuk Pop Art, merupakan sebuah bentuk komunikasi visual "tidak berbeda dalam bermacam-macam bentuk dari komunikasi visual lainnya".

Budaya populer cenderung menjamur di masyarakat sebagai bentuk ekspresi yang di dominasi terhadap halhal populer, ditampilkan sebagai ungkapan dari sebuah hal yang kuat dan sedang 'trend' di masyarakat, dan terkadang menjadi sebuah budaya baru yang berbeda dengan budaya yang kuat dan sudah ada di masyarakat lainnya.Konsep dan ide yang diangkat dalam Pop Artada dalam bentuk yang ditujukan untuk masyarakat luas, yang mudah dipahami oleh mereka. Mengangkat dari berbagai macam hal keseharian manusia, seperti ide komik oleh Lichtenstein (dalam Whiting, 1997:103) mengangkat Pop Art dari genre komik romansa untuk dewasa, dengan isi yang berupa konten cinta dan perang, dimana ikon perempuan sangat kental di karya-karyanya.Henri Dauman (Whiting, 1997:xiii) mengangkat "Cambell's Chicken Soup" dalam pamerannya yang berjudul "You Think This is Supermarket?" tanggal 20 November 1964, dimana ketika itu produk sup ayam kaleng sangat banyak di masyarakat. Sedangkan, Andy Warhol (Whiting, 1997:146) melukis Marilyn 
Monroe, Elizabeth Taylor, Elvis Presley, dan banyak bintang film yang sedang tenar di tahun 1960-an. Warhol juga, layaknya Dauman, juga membuat kritik sosial atas produk massal Coca-Cola (Gambar 3), atas sebuah sindiran terhadap produk kapitalis yang berkuasa. Bisa dikatakan bahwa Pop Art memiliki caranya sendiri untuk memunculkan ideide dari Pop Art sebagai sebuah seni yang ada dan berkembang di masyarakat.

Perkembangan Pop Art yang demikian cepat, membuat Pop Art mengalami masa surut yang relatif cepat beberapa tahun berikutnya.Ini disebabkan salah satunya karena Pop Art memang sangat cepat berkembang karena spontanitas reaksi pada saat itu, secara sosial, maupun momentum di Amerika maupun Inggris.Selain itu, (Wardana, 2012:19) Pop Art sebagai sumber pemikat dan ditunggangi kepentingan "Industri Massa" yang menargetkan anak muda sebagai calon konsumennya. Pop Art menjadi tidak lebih dari sekedar komoditas, sehingga kemudian dianggap bukan lagi sebagai bentuk kritik pada masa-masa awal kelahirannya. Cenderung menjadi alat saja, bukan sebuah seni yang mengandung makna.

\section{Pop Art di Indonesia}

Di Indonesia, karya seni rupa yang mengusung gaya Pop Art telah merebak pada sekitar tahun 70-an. Munculnya "Seni Rupa Baru 1975," ditandai dengan adanya pameran seni rupa yang berjudul "Kepribadian Apa," menandakan Pop Art masuk ke Indonesia. Tokohnya ada Bonyong Munni Ardhi, Ris Purwana, Budi Sulistyo, Iskandar Suryaputra, Gendut Riyanto, dll. Bonyong (pada wawancara 2016) mengatakan bahwa pada pameran "Kepribadian Apa," merupakan bentuk kritik terhadap masyarakat seni rupa yang mengharuskan memiliki ciri khas dalam membuat karya seninya, disamping juga mengungkapkan kritik terhadap kehidupan masyarakat sekarang yang cenderung tidak pernah puas. Dalam tata hidup sekarang ini saya mulai merasakan sesuatu yang mendeg, ini dalam segala hal, ngga tau itu soal politik, soal ekonomi, hukum, agama, seni, dll. dimanasecara ketidak "puasan" kita sebagai manusia, dengan daya kreatif kita, kita selalu menghendaki perubahan terus menerus, pembaharuan demi untuk segala macam "keseimbangan" ini terasa sekali bila apa-apa nya telah menjadi patokan-patokan, dogma, tata cara yang sudah jelas, mengulang-ulang, lebih-lebih kita sadar telah bertahun-tahun kita pakai dogma-dogma, aturanaturan seperti itu-itu juga. (Ardhi dalam katalog Pameran Kepribadian Apa, hlm. 10)

Walaupun dalam Pameran Seni Rupa "Kepribadian Apa" tidak pernah ada kata Pop Art didalamnya, namun semangat dalam pameran tersebut, halhal yang diangkat dalam pameran tersebut, dan jiwa yang ada merepresentasikan sebagai Pop Art. Narsen Afatara (dalam wawancara 8 Juli 2016) berpendapat, dalam sebuah gaya seni rupa, akan merepresentasikan "Jiwa Jaman" masing-masing. Dalam pameran seni rupa "Kepribadian Apa" mencoba membuka jiwa jaman yang baru, yang juga menggunakan nuansa Pop Art untuk menunjukkan era baru seni rupa di Indonesia. Seperti menggunkan gambar pantat untuk memberikan isi terhadap karya seninya, yang diambil dari foto. 


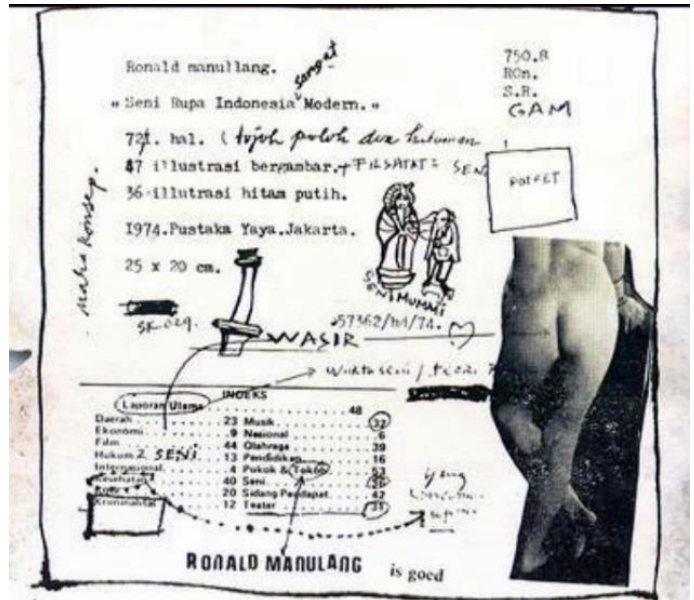

Gambar 5.

Gambar Kepribadian Apa. Merupakan gambar dalam katalog Pemeran Seni Rupa "Kepribadian Apa (1977)" (Gambar hasil Repro Foto dari

IVVA: Katalog Kepribadian Apa)

Hal ini memberikan angin segar kepada Seni Rupa Indonesia untuk berkembang, setelah sebelumnya dikuasai aliran romantik dari senimanseniman belanda dan peperangan ideologi dengan LEKRA (Lembaga Kebudayaan Rakyat). Pada dekade berikutnya, dimana seniman rupa-nya yang berada pada angkatan 1990-sekarang, kelahiran 1955an dan 1975-an, merajai seni rupa modern Indonesia. Lulusan akademi Bandung dan Yogya menyebar menjadi pengajar di seluruh akademi Seni Rupa yang kemudian dibentuk. Kala inilah, muncul keterbukaan Indonesia atas masuknya segala macam jenis seni rupa dunia kontemporer. Diadakannya pameranpameran yang berkelanjutan tentang Seni Rupa kontemporer, dan begitupu setelahnya. Salah satunya jenis seni rupa dunia kontemporer yang masuk Indonesia adalah Pop Art Amerika (Sumardjo, 2009:140). Salah satu seniman Indonesia lainnya yang bergerak dalam bidang $P o p$ Art adalah Bambang Pramudiyanto. Konsisten dalam membuat lukisan Pop Art dari tahun 1990-2000an.

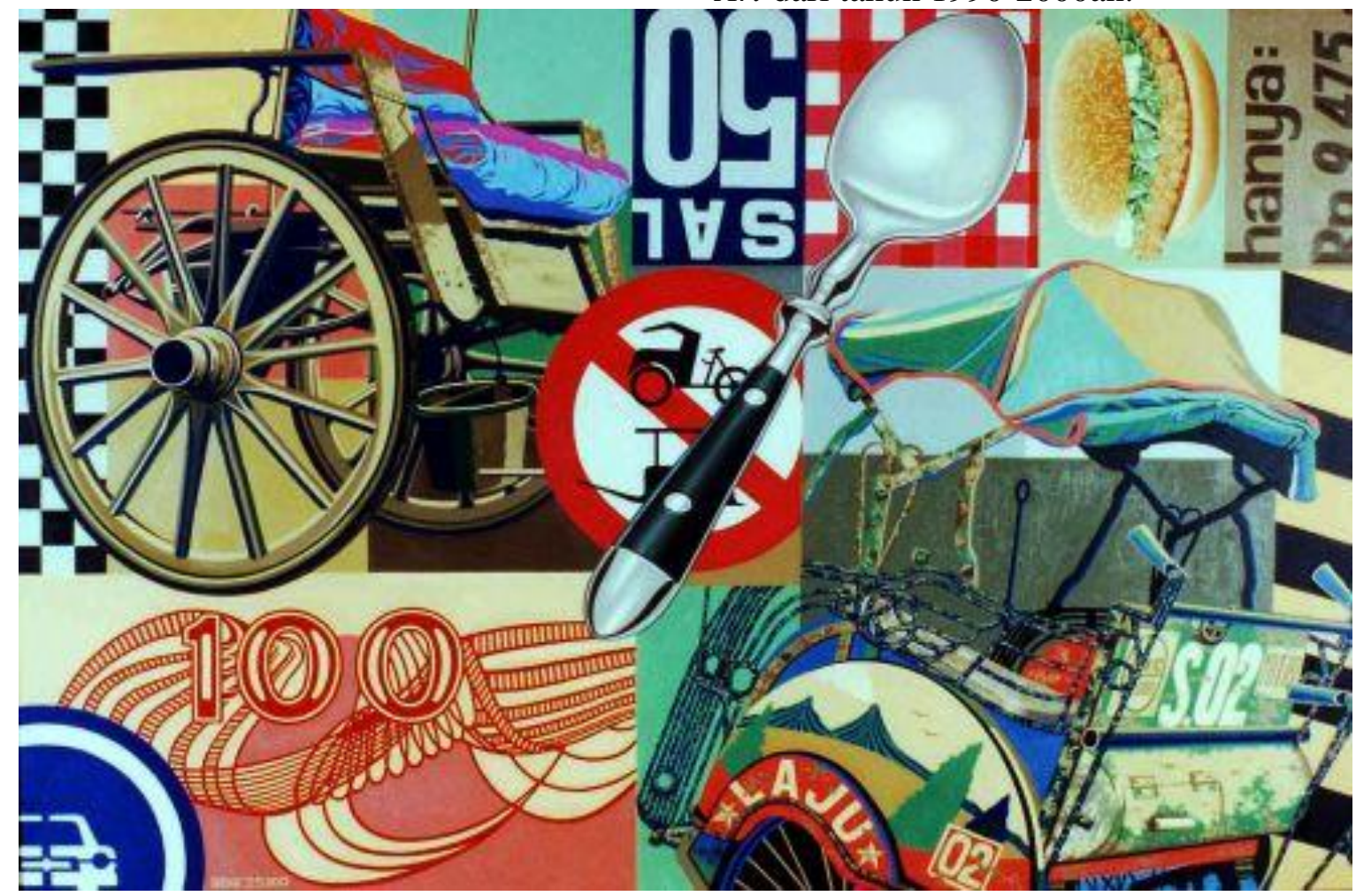

Gambar 6.

Ways of Life. Bambang Pramudiyanto.2000. 100x150 cm, dalam Edwin's Gallery.

(Foto http://archive.ivaa-online.org/img/artworks/small/1339146665.jpg diambil pada 4:56 WIB, 20

Agustus 2016) 
Pada saat itu juga Pop Art masuk ke ranah desain. Majalah Musik Aktual, salah satumajalah musik yang sangat populer di kalangan generasi muda menyerap gaya Pop ke dalam bentuk ilustrasi, poster, dan desain halaman/rubrik yang ada dalam majalah tersebut (Sachari \& Sunarya dalam Wardana, 2012: 19-20).Seiring berjalannya waktu, pop-art masuk dalam desain grafis di Indonesia, dimana salah satunya, majalah desain grafis "Concept" edisi 17, mengangkat tentang Pop Art.

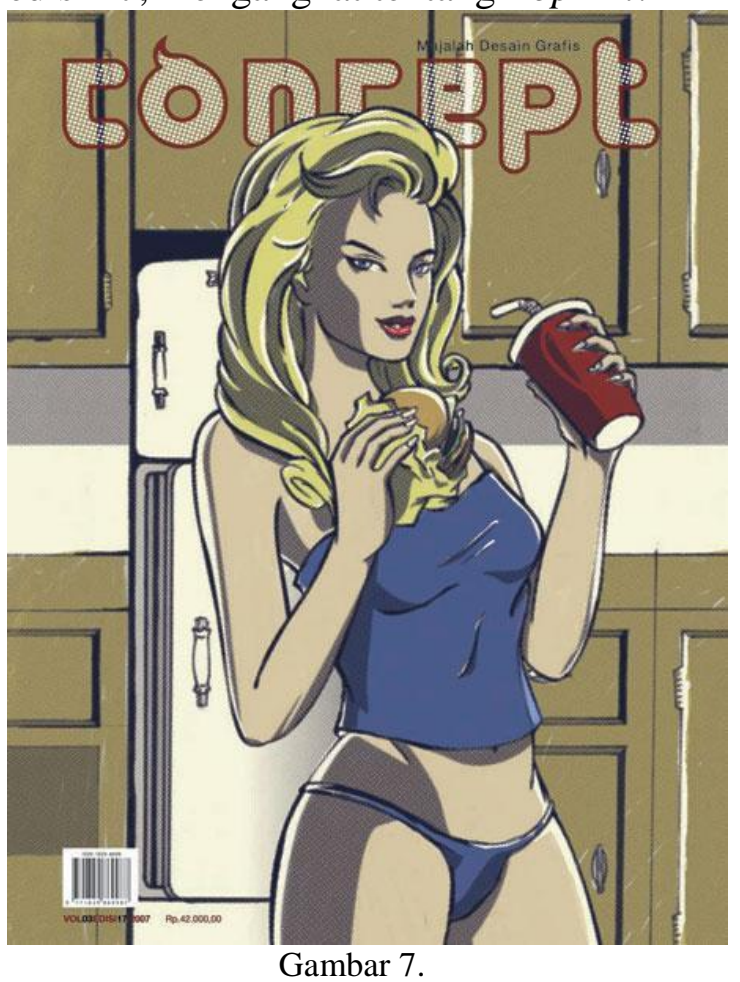

Long Lasting Pop Art!.Art Director: Vera

Tarjono, Illustrator \& Designer: Denny Kurniawan. 2007. Cover Majalah Concept Edisi

17. (Sumber: Gambar hasil Repro Foto dari Wardana (2012:20))

Dalam kata pengantar majalah ini, dijelaskan oleh team kreatif dari majalah Concept edisi 17:

Cewek ini tak hanya diibaratkan sebagai sebuah produk yang menarik perhatian (seperti brand), tapi juga mewakili sosok yang tanpa sadar dalam kesehariannya terikat beragam brand mulai minum Coca-Cola, makan $M c$
Donald, berbalut Victoria's Secret, dan banyak lagi.Gaya ilustrasi yang dipilih oleh tim kreatif adalah pop-art, karena menurut mereka desain bergaya pop-art memiliki sifat yang long-lasting, memiliki dampak yang panjang, walaupun sudah surut. Buktinya banyak sekali poster-poster yang sekarang beredar, masih menggunakan style dan warna pop-art.

Penggunaan karakter komik begitu kuat dalam cover majalah Conceptedisi 17 ini. Cover majalah ini, berusaha menarik pandangan audiensnya melalui gaya komikal dengan obyek yang provokatif, dengan menggunakan warna yang mencolok, layaknya Pop Art di Amerika. Dengan menggunakan olah visual komik, tim kreatif Concept berusaha menampilkan menggunakan budaya massa, berupa komik, untuk menampilkan sebuah bentuk karya Pop Art yang digunakan untuk khayalak ramai, yang tujuannya untuk menarik Audience agar tertarik membaca isi dari majalah tersebut. Ini yang menjadikan bukti bahwa, dunia desain grafis di Indonesia telah dimasuki ide-ide Pop Art sebagai sebuah visual yang digunakan dalam komoditas yang berupa majalah.

Pada perkembangannya, Pop Art kemudian diubah oleh Wedha Abdul Rasyid sebagai sebuah gaya yang dinamakan Wedh's Pop Art Portrait (WPAP). Melalui komunitasnya, WPAP menyebarkan gaya Pop Art ala Wedha sebagai sebagai sebagai identitas Pop Art Indonesia. 


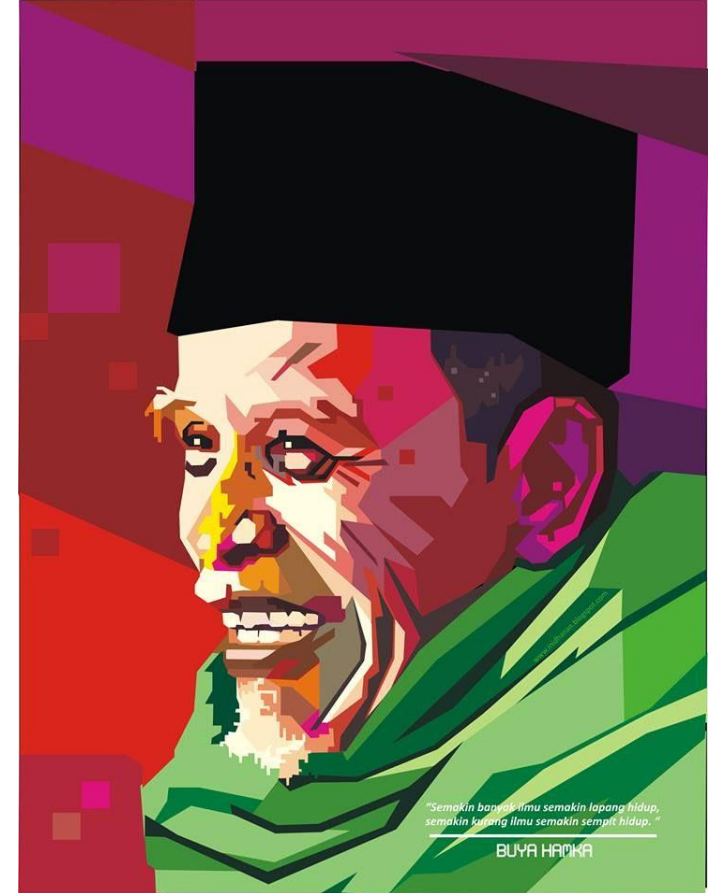

Gambar 8. Contoh Karya WPAP: Buya Hamka WPAP (Sumber: diambil dari

WPAPCommunity.com pada tanggal 14 Maret 2016 jam 18:32 WIB)

\section{SIMPULAN}

Pop Art berkembang sangat pesat semenjak pemikiran Industri di Amerika dan Inggris teraplikasi dalam kehidupan keseharian masyarakatnya. Seniman, khususnya seniman rupa, tidak tinggal diam dalam industrialisasi ini, ide-ide tentang menampilkan keadaan masyarakat melalui seni, yang juga sebagai bentuk perlawanan abstrak ekspresionis yang kala itu merebak, memberikan celah yang besar terhadap pelaku seni Pop Art memberikan pandangan ide-ide baru dalam karyakaryanya. Kemunculan-kemunculan Pop Art ini merebak, walaupun ternyata Pop Art harus mati muda, untuk menebus kesalahannya, sebagai pengkritik kehidupan sosial saat itu pada dunia Industri, yang terjadi pada 1970-an. Seni ini malah menjadi senjata untuk mengenalkan produknya kepada anak muda di Amerika dan Inggris.
Pada sisi lain Pop Art juga berkembang dan merebak di Indonesia. Banyak karya-karya visual yang menggunakan Pop Art sebagai sebuah inspirasi, terbukti dengan adanya majalah yang secara khusus menggunakan Pop Art sebagai gayanya dalam satu edisi khusus. Pada dekade berikutnya, di abad ke-20, Pop Art muncul dengan istilah Wedha's Pop Art Portrait (WPAP). Hal ini juga menjadi bukti bahwa Pop Art telah masuk ke Indonesia sebagai sebuah gaya maupun sebagai teknik.[]

\section{DAFTAR PUSTAKA}

Buku

Ford, Carin T. 2001. Andy Warhol: Pioneer of Pop Art. New Jersey: Enslow Publishers

Harrison, Sylvia. 2001. Pop Art and the Origins of Post-Modernism. New York: Cambridge University Press

Hauser, Arnold. 1985. Sociology of Art. Kenneth J. Northcott (Translator). Chicago: University of Chicago Press

James, Jamie. 1996. Pop Art. Singapura: Borders Press

Lippard, Lucy R. 1991. Pop Art. London: Thames and Hudson Ltd.

Sipperley, Keli. 2013. A Look at Pop Art. Minnesota: Rourke Educational Media

Sumardjo, Jakob. 2009. Asal Usul Seni Rupa Modern Indonesia. Bandung: Penerbit Kelir

Whiting, Cecile. 1997. A Taste for Pop: Pop Art, Gender, and Consumer Culture. Cambridge: Cambridge University Press

Malah, Journal, dan Dokumen Cetak Lainnya 
Wardana, Ketut Nala Hari. "Gaya Pop Art pada Karya Desain Grafis di Indonesia", dalam Jurnal PRASI Vol.7 No. 14 Edisi Juli-Desember 2012.

Katalog Pameran Kepribadian Apa, 1977

Kleden, Ignas. Kebudayaan Pop: KritikdanPengakuandalamMajala hPrismaedisi Mei 1978, hlm. 3-8. Jakarta: Prisma-LP3ES, 1978.
Narasumber

Narsen Afatara, 68, (2016) dosen dan pengamat Seni Rupa Indonesia. Jurusan Seni Rupa Murni, Fakultas Seni Rupa dan Desain, Universitas Sebelas Maret Surakarta

Bonyong Munni Ardhi, 56 tahun, (2016) pengamat dan pelaku Seni Rupa Baru Indonesia 1970-an 